\title{
Relationship Between the Cultivation and Incentive Mechanism of Senior Educational Talents
}

\author{
https://doi.org/10.3991/ijet.v16i22.26879 \\ Jialin Zuo, Wei Lu, Chunxu Jia( ${ }^{(凶)}$ \\ Hebei Jiaotong Vocational and Technical College, Shijiazhuang, China \\ zlwei1220@163.com
}

\begin{abstract}
The attraction and mobility of senior educational talents hinge on the talent cultivation and incentive mechanism of various enterprises. If the mechanism is imperfect, the talents will be less active and creative in work, and the enterprises will underperform in the long term. This paper combines literature review, questionnaire survey, and mathematical analysis to summarize the current situation of the cultivation and incentive mechanism of senior educational talents in an enterprise in a region, and analyze the defects of the existing mechanism. The results show that: the senior educational talents have not received sufficient compensations or incentive measures; the employees do not have a smooth promotion channel; the enterprise fails to issue clear and innovative reward policies. To address these defects, this paper proposes improvement measures and optimization schemes: To boost the enthusiasm and creativity of employees in work, the enterprises should give full play to the personal values of senior educational talents, strive to introduce more excellent talents, and establish a sound salary distribution system and reasonable promotion polices. The research results lay a theoretical basis for enterprises to cultivate and absorb the necessary senior educational talents.
\end{abstract}

Keywords-senior educational talents, talent cultivation, incentive mechanism, incentive theory

\section{Introduction}

China has witnessed fast development in society, economy, politics, culture, and other fields in recent years, and the cultivation of senior educational talents has played a very important role in this prosperity, however, the talent cultivation and incentive mechanism is also facing great challenges [1-3]. Higher education is the main channel for colleges and universities to convey senior talents to the society, and it gives instructions to the interaction between the adjustment of social and economic structure and talent cultivation in a country [4-7]. Now, the senior educational talents have become a core demand of the human resource management of social enterprises and educational institutions, and they provide important technical support for the development of higher education and enterprises. For a certain region or a certain enterprise, the introduction of senior educational talents, or the preferential fiscal and taxation policies cannot get 
to the root of the problem of talent shortage and loss, while the cultivation and incentive mechanism of senior educational talents is the fundamental measure to solve this problem [8-11].

Senior educational talents and senior skilled talents exert important roles in the development of hi-tech industries and enterprises, and their effects are mainly manifested in aspects such as solving technical problems, upgrading techniques, and increasing economic benefits of the enterprise [12-16]. At present, social system, economic development structure, and social education mode are highly dependent on the development of science and technology, and such situation requires more high-quality, high-level, and high-competence technological talents to provide solid support for the development of social economy [17-20]. As a result, the cultivation of senior educational talents will play a pivotal role in it [21-23]. However, in most regions, the situation of shortage and loss of senior educational talents is still serious, and only by establishing an effective cultivation and incentive mechanism can the demand of highly skilled talents be guaranteed.

Based on current situations of higher education mode and talent cultivation and incentive mechanism, this paper draws on foreign and domestic experience in senior educational talent cultivation and gives a few measures for improving the current educational talent cultivation strategies; then, aiming at the requirement of talent development, this paper proposes a talent incentive mechanism, in the hopes of providing more senior educational talents and high-quality professional skilled talents, and laying a solid basis for promoting social economy development and optimizing the environment for the talents.

\section{Theory of senior educational talent cultivation and incentive}

\subsection{Talent cultivation and incentive mechanism}

As the primary driving force of social development and technological progress, senior educational talents have always occupied the dominant position in social production. With the popularization of Internet and the emergence of new technologies such as big data, cloud computing and blockchain, the technologies in the social development system are undergoing unprecedented innovation and reform, which lays a solid foundation for enhancing the core competitiveness of future technologies. Colleges and universities, financial companies, manufacturing enterprises, and scientific research institutions are all in need of constant supply of senior educational talents with innovation ability and profound professional knowledge. Senior educational talents should have the following features (see Figure 1): comprehensive and solid professional knowledge and skills, excellent innovation ability and exploration spirit, good teamwork ability, and sense of responsibility, etc. 


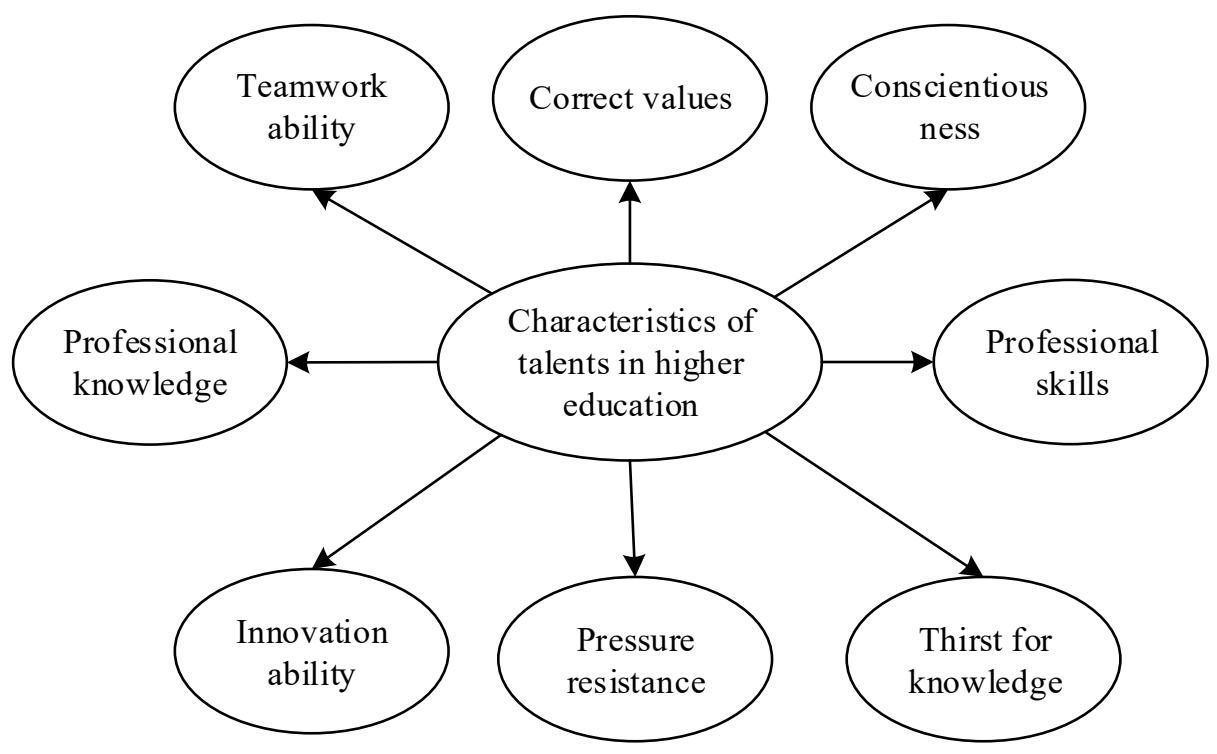

Fig. 1. Features of senior educational talents

Talent incentives include internal incentives and external incentives. Internal incentives usually refer to motivate talents through their interest and hobbies, and external incentives refer to motivate talents through benefits and rewards. Figure 2 gives the common process of individual incentives. The incentive mechanism mentioned in this paper means to adopt certain means and methods to encourage the talents and reveal the evolutionary law of the internal relationship between individuals after they have undergone certain reactions or connections.

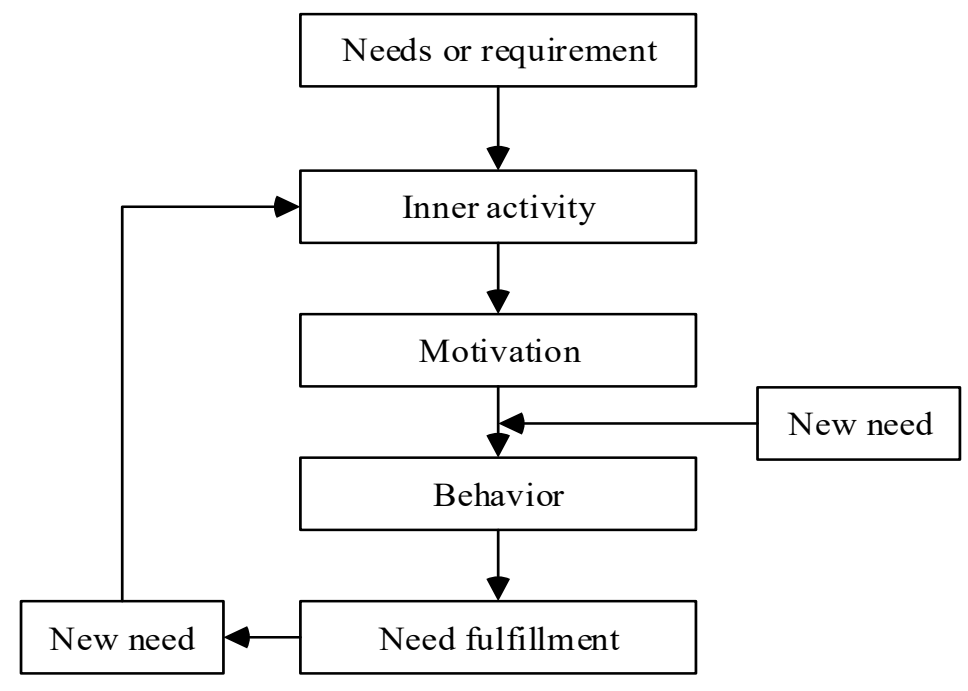

Fig. 2. Common process of individual incentives 


\subsection{Theories of incentives}

The theories of incentives are divided into three types, the process-type, the contenttype, and the adjustment-type. The first two types study how to trigger the motivation and enthusiasm of individuals, and the last type focuses on the adjustment and transformation of individuals' behavior and enhancement of the correct behavior of people.

The process-type incentive theory includes the self-determination theory, the equity theory, the goal setting theory, and the Vroom's expectancy theory. The self-determination theory holds that people's self-selection is more important, and incentive mechanism can give more autonomy to talents; the equity theory believes that the fair distribution of welfares and rewards can influence people's psychology and intrinsic motivation, and the rationality of rewards will affect people's subsequent work status and efforts; the goal setting theory argues to set goals for individuals first and then make them realize those goals, and this is a more direct and effective way to trigger talents' enthusiasm; the expectancy theory thinks that people's behavior and choices rely more on their expectations for the outcome of the behavior.

The content-type incentive theory includes the achievement motivation theory, the two-factor theory, and the hierarchy of needs theory. The achievement motivation theory believes that people not only have basic needs for survival, but also needs for rights, needs for achievement, and needs for belonging, and individuals hope to obtain a sense of accomplishment through their own efforts; the two-factor theory emphasizes on motivating and triggering the initiative of individuals from both internal and external aspects; the hierarchy of needs theory proposes that the needs of individuals can be divided into 5 hierarchies according to their level and importance, see Figure 3.

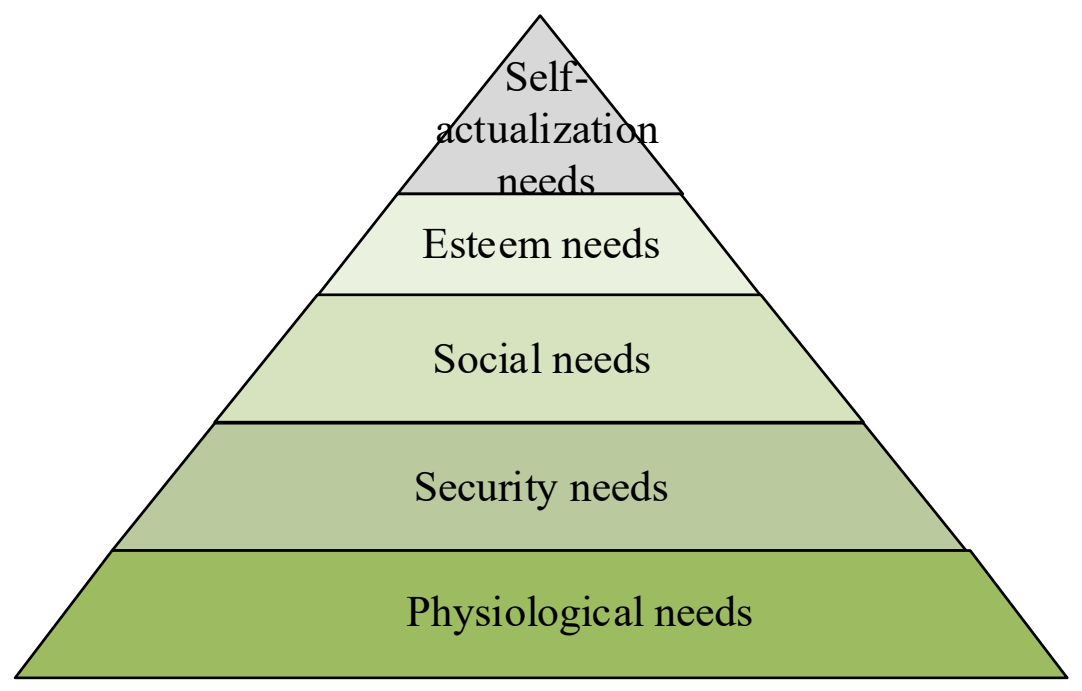

Fig. 3. Hierarchy of needs 


\section{Cultivation and incentive mechanism for senior educational talents}

\subsection{Senior educational talent cultivation mode}

The cultivation of senior educational talents includes two aspects: one aspect is to cultivate learning-type talents who can accept and learn the existing knowledge, efforts should be made to improve the learning-type talents' understanding of the objective operation of the world and the laws of social development, so that they could solve the various problems existing in the process of social development; the other aspect is to cultivate senior-level talents, namely the type of talents who can discover and create knowledge, efforts should be made to train such creation-type talents so that they could create new knowledge and skills based on the knowledge they learnt and thus serving social advancement and human development. In the current education system, undergraduate education and education of earlier stages belong to the knowledge learning education which aims to impart mature theories and practical knowledge to students, so that they could form a better cognition of the society; while the education of the master and doctor stages belongs to the innovative learning education which exercises students' ability to discover problems and solve the problems based on the knowledge and methods they learnt, and to create new theories and technologies.

Senior educational talents should have excellent comprehensive abilities, and the cultivation goals of senior talents should contain the various abilities shown in Figure 4 , including the ability to accept existing knowledge and create new knowledge, the ability to combine theory with practice, the ability to integrate and summarize the knowledge system, the ability to apply theory to practice, the ability to draw analogies from existing knowledge, and the social cognitive ability, etc.

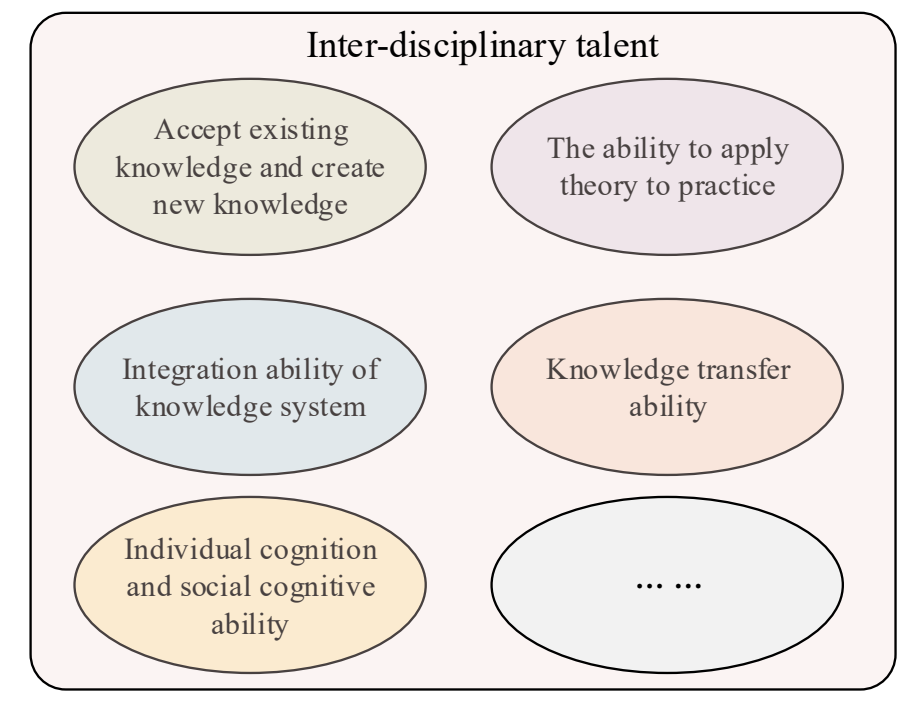

Fig. 4. Cultivation goals of senior educational talents 
In different periods of social and economic development, social productivity and the development of science and technology basically keep at a same level, the development of science and technology and the social transformation have improved the social productivity and economic levels. Senior educational talents and high-quality skilled talents are the promoters of technological development, they play an irreplaceable role in technological progress and social changes. Summarizing the types of talents required by society of different periods is beneficial to constructing a system for cultivating senior educational talents. In modern society with developed information and network technologies, pooling innovative, knowledgeable, and skilled talents has become the core competitiveness of enterprises, and social progress requires to update and reform this senior educational talent cultivation mode constantly.

\subsection{Basic situation of senior educational talents}

Taking the talent cultivation of a city in eastern China as an example, this study analyzed the senior educational talent structure of the city and the current situation of talent cultivation, then it explored the reasons for the shortage of senior educational talents and discussed the talent introduction strategies adopted by the city. According to statistics of talents in the region, in the recent five years, the distribution of educational background of talents in the region is shown in Figure 5, with the increase in the demand for talents, the study region has introduced more senior educational talents, the proportion of talents with a bachelor degree increased from $44 \%$ to $51 \%$, the proportion of talents with a master degree increased from $12 \%$ to $15 \%$, and the proportion of talents with a doctor degree increased from $4 \%$ to $7 \%$.

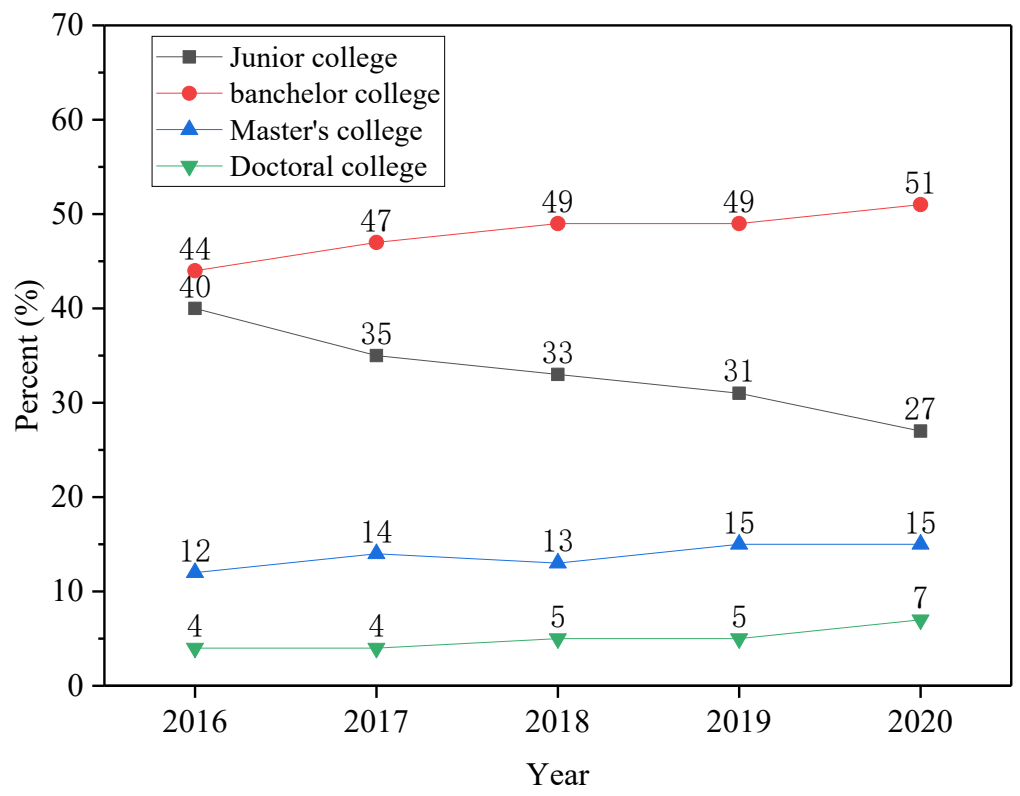

Fig. 5. Distribution of educational background of senior educational talents in recent five years 
In 2020, among the senior educational talents in the region, the proportions of talents with a college diploma, bachelor degree, master degree, and doctor degree were respectively $32 \%, 46 \%, 15 \%$, and $7 \%$, as shown in Figure 6 . Talents with a bachelor's degree or above accounted for $68 \%$, however, as for masters and doctors, namely talents focusing on knowledge creation, they only took a small proportion of $22 \%$ in all senior educational talents. The numbers of bachelor, master, and doctor talents are increasing year by year, while the number of talents with a college diploma is reducing over the years. However, in order to vigorously develop the science and technology of the region and promote the innovation-type social economy, the study region still needs to cultivate and introduce more innovation-type master-degree and doctor-degree talents according to the talent requirements of each industry.

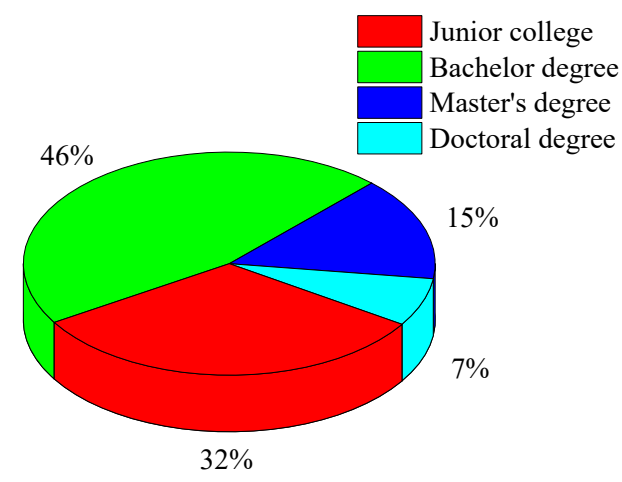

Fig. 6. Statistics of educational level of talents

To figure out the working years and income of senior educational talents in the region, this study selected a financial enterprise in the region for investigation, and the statistics are shown in Figure 7. Most of the senior educational talents working in this enterprise have a work experience of more than 5 years, accounting for $62 \%$; and the number of talents with a work experience of less than 1 year accounted for $3 \%$; talents with a work experience of 1-3 years and 3-5 years accounted for $14 \%$ and $21 \%$, respectively. As can be seen from the figure, talents in the enterprise generally have worked for a long time, which indicated that the enterprise can keep senior educational talents, and the loyalty of employees is relatively high. 


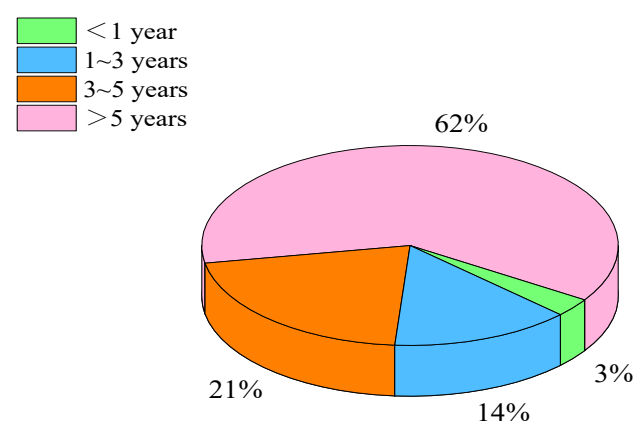

Fig. 7. Statistics of working years of senior educational talents

Figure 8 shows the statistics of the annual income of senior educational talents of the surveyed enterprise. $19 \%$ of the employees have an annual income of less than 100,000 yuan; the proportion of employees with an annual income between 100,000 and 200,000 yuan is $53 \%$; the proportion of employees with an annual income between 200,000 and 300,000 yuan is $21 \%$; and $7 \%$ of the employees have an annual income of more than 300,000 yuan. According to the data, overall speaking, the annual income of senior educational talents in the enterprise is not high, only $29 \%$ of the employees have an annual income of more than 200,000 yuan, and $19 \%$ of the senior educational talents have an annual income of less than 100,000 yuan. To a certain extent, the survey results indicate that the salary and welfare of the enterprise is not good enough, the imbalance of pay and gain will limit the creativity and enthusiasm of senior educational talents in their work.

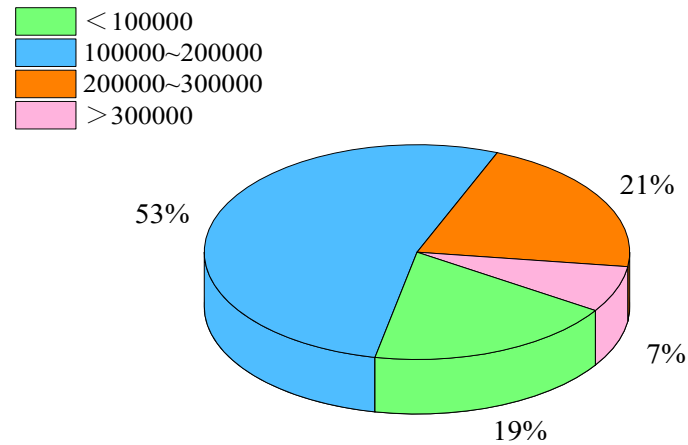

Fig. 8. Statistics of annual income of senior educational talents

\subsection{Current situation of cultivation and incentive mechanism of senior educational talents}

This paper analyzed the current situation of senior educational talent cultivation mechanism in the study region from the perspectives of talent cultivation goal, meth- 
ods, and ways. First, the goal of senior educational talent cultivation is to convey professional, innovative, and highly skilled talents to various industries such as scientific research, production, finance, education, and medicine, etc., to promote social production and technological progress. The methods and ways of senior educational talent cultivation are mainly to introduce talents from higher educational schools or recruit from society. For the professional talents graduated from colleges and universities, the employer enterprises' professional skill and practical ability training programs could cultivate the basic skills of newly recruited employees so that they could better serve the enterprise. At the same time, the enterprise takes corresponding measures to solve talent shortage problem inside the company, uses active measures to absorb and form professional talent teams, and actively organizes various activities to enhance the professional skills of enterprise employees and broaden their vision.

This paper also summarized the talent incentives of the survey enterprise, the incentive mechanism of the enterprise is mainly achieved through salary and welfare, and vocational training. In the surveyed enterprise, the salary and welfare are related to the performance of the employees, and there are differences in the basic salary and performance salary of employees at different job positions and of different performance, assessment, and skill levels. In addition, other corporate subsidies, such as communication and transportation subsidies, year-end bonus, and other incentive wages, are paid in proportion to the position level of the employees. Figure 9 shows the composition of the salary and welfare of senior educational talents in the surveyed enterprise. Survey results show that the basic salary of the talents is mainly determined by their job position levels in the enterprise, the higher the job position level, the higher the salary level; the greater the difference in the job position levels, the greater the difference of the salary levels of the talents.

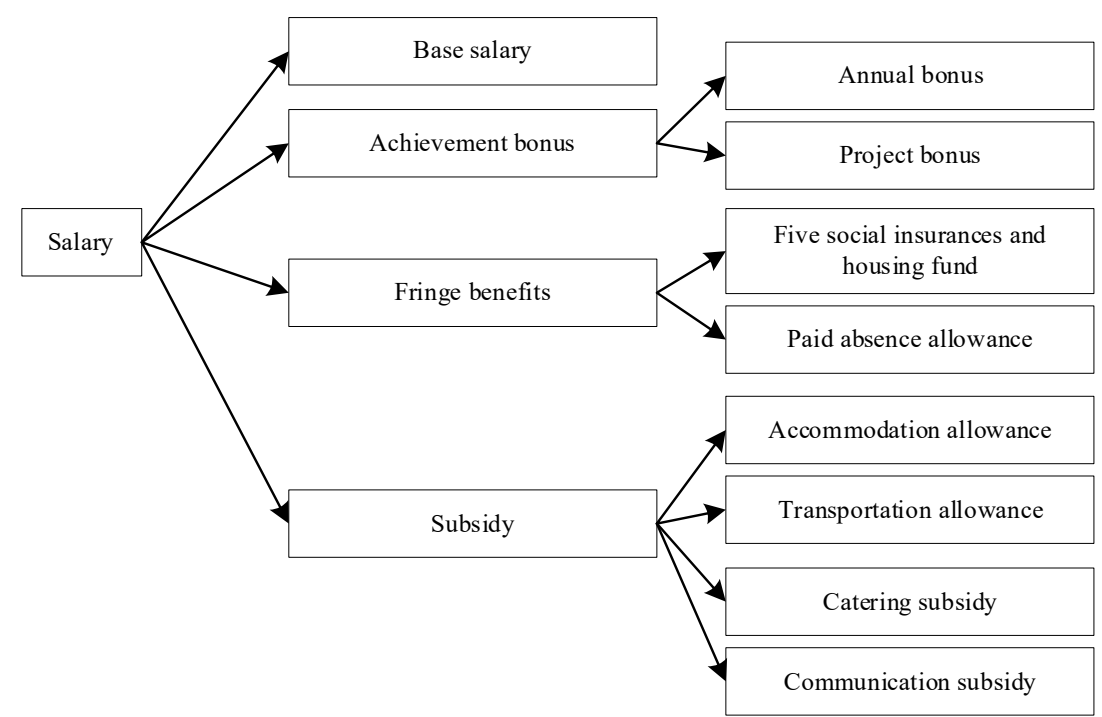

Fig. 9. Composition of salary and welfare of senior educational talents in the surveyed enterprise 
In order to improve the skill level and other relevant comprehensive ability of talents and employees, the enterprise organizes the senior educational talents to participate in vocational training on a regular basis to stimulate their innovativeness and working enthusiasm through vocational training and corporate care programs. Besides, the enterprise hopes that the senior educational talents could form good working habits and an optimistic attitude, learn and accept new knowledge and technologies continuously, and combine theory with practice to serve the development of the enterprise.

To figure out the employees' satisfaction with the salary level and incentive mechanism of the enterprise, this paper combined questionnaire survey with data analysis. Questions in the questionnaire included "senior educational talents' satisfaction with the talent cultivation mechanism of the enterprise", "senior educational talents' satisfaction with the salary level of the enterprise", and "senior educational talents' satisfaction with the promotion channel of the enterprise", etc., due to space limitation, here this paper only gave detailed analysis of these three questions. The satisfaction degree was scored 1-5 points, 1 point stands for totally not satisfied, 2 points stand for partially not satisfied, 3 points stand for basically satisfied, 4 points stand for relatively satisfied, 5 points stand for totally satisfied. A total of 150 questionnaires were sent out and 150 valid questionnaires were returned.

As shown in Figure 10, employees who are totally not satisfied and partially not satisfied with the talent cultivation mechanism of the enterprise accounted for $15 \%$ and $28 \%$, respectively; $37 \%$ of the senior educational talents are basically satisfied with it, $16 \%$ are relatively satisfied with it, and only $4 \%$ are totally satisfied with it. The results show that most employees believe that the cultivation mechanism of the enterprise needs to be improved and optimized.

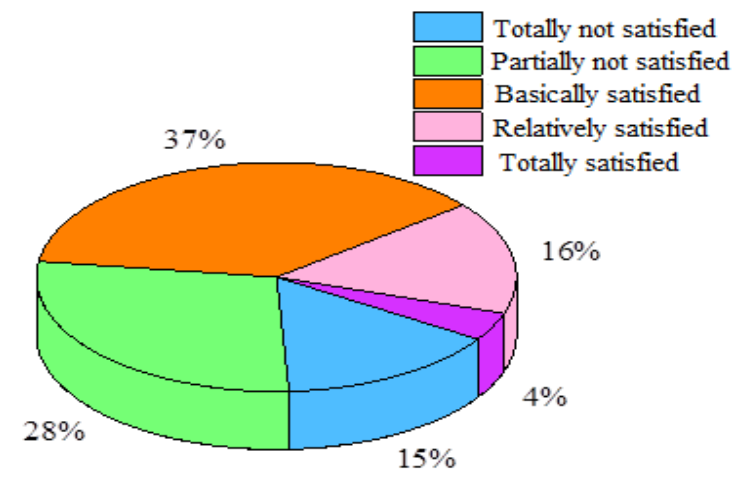

Fig. 10. Statistics of senior educational talents' satisfaction with the talent cultivation mechanism of the enterprise

Figure 11 and Figure 12 respective give the statistical results of the senior educational talents' satisfaction with the enterprise's salary level and promotion channel. According to Figure 11, employees who are totally not satisfied and partially not satisfied with the salary level of the enterprise accounted for $21 \%$ and $23 \%$, respectively; $32 \%$ of the employees are basically satisfied with it, and $18 \%$ and $6 \%$ of them are relatively satisfied and totally satisfied with it. Most employees think that the enterprise should 
consider to further increase the basic salary and welfare level of senior educational talents. According to Figure $12,8 \%$ and $21 \%$ of the senior educational talents are not satisfied or partially not satisfied with the promotion policy of the enterprise, and only $4 \%$ of the employees are totally satisfied with it. The promotion policy of an enterprise directly affects the work enthusiasm and creativity of its employees, therefore, in order to better retain and attract talents, it is necessary to optimize internal promotion policy and incentive mechanism.

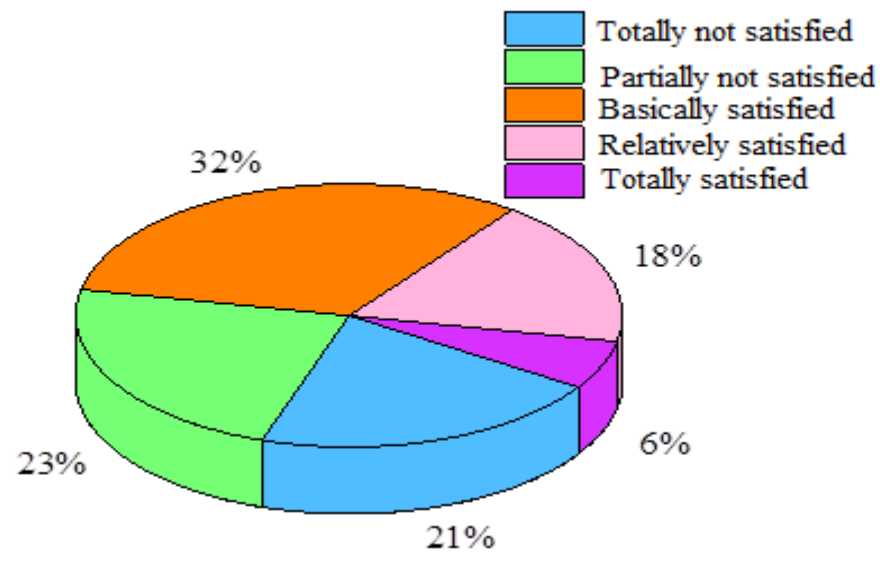

Fig. 11. Statistics of senior educational talents' satisfaction with the salary level of the enterprise

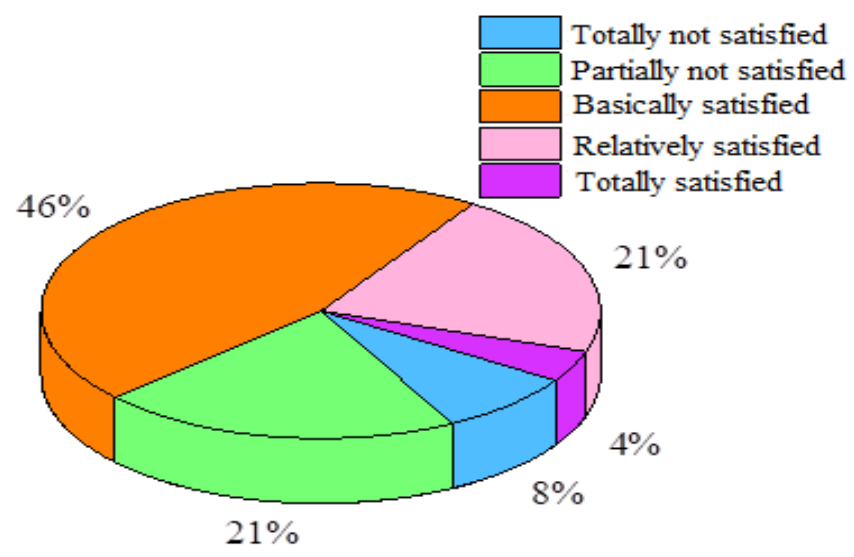

Fig. 12. Statistics of senior educational talents' satisfaction with the promotion channel of the enterprise 


\section{Conclusions}

Based on a summary of the current situation of talent cultivation and enterprise incentive mechanism, this paper conducted an in-depth research on the relationship between senior educational talent cultivation and incentive mechanism, it analyzed the problems existing in talent cultivation and incentive mechanism, and proposed corresponding optimization solutions. The main conclusions are as follows:

1. The basic salary of the senior educational talents is mainly determined by their job position levels in the enterprise, the higher the job position level, the higher the salary level; the greater the difference of the job position levels, the greater the difference of the salary levels of the talents.

2. Most employees think that there're many problems with the enterprise's cultivation mechanism, salary level, and promotion channel; the attitude and working enthusiasm of the employees have an impact on the long-term development and economic benefits of the enterprise, which requires special attention.

3. In terms of talent cultivation and incentive mechanism, the enterprise should optimize the cultivation policy and mechanism of senior educational talents, enhance the skill training of employees, expand the training scope, formulate fair and reasonable salary distribution and performance assessment policies, and enlarge talent promotion space, in this way, the creativity and enthusiasm of talents could be exerted to the greatest extent.

\section{$5 \quad$ References}

[1] Li, L., Zhang, K., Li, T. (2020). A Performance Analysis Model for the Training and Education of Information Security Talents, International Journal of Emerging Technologies in Learning, 15(5), 140-155. https://doi.org/10.3991/ijet.v15i05.13329

[2] Zhan, Y., Zhang, J., Li, P., Xia, Y. (2019). Crowdtraining: Architecture and Incentive Mechanism for Deep Learning Training in the Internet of Things. IEEE Network, 33(5): 89-95. https://doi.org/10.1109/mnet.001.1800498

[3] Kong, F.W. (2020). A Fuzzy Information Evaluation Model for Scientific Innovation of Art Talents in Colleges. International Journal of Emerging Technologies in Learning, 15(12), 217-229. https://doi.org/10.3991/ijet.v15i12.14529

[4] Tabucanon, A.S., Sahavacharin, A., Rathviboon, S., Lhaetee, H., Pakdeesom, D., Xue, W., Charmondusit, K. (2021). Investigating the critical issues for enhancing sustainability in higher education institutes in Thailand. International Journal of Sustainable Development and Planning, 16(3): 503-514. https://doi.org/10.18280/ijsdp.160311

[5] Sakaliuk, O.Y., Trishyn, F.A. (2021). Mathematical model and efficiency of courses timetable creation process. Mathematical Modelling of Engineering Problems, 8(3): 377-385. https://doi.org/10.18280/mmep.080306

[6] Vankayalapati, R., Ghutugade, K.B., Vannapuram, R., Prasanna, B.P.S. (2021). K-means algorithm for clustering of learners performance levels using machine learning techniques. Revue d'Intelligence Artificielle, 35(1): 99-104. https://doi.org/10.18280/ria.350112 
[7] Xu, Z.H. (2020). Construction and optimization of talent training quality based on data mining. Ingénierie des Systèmes d'Information, 25(4): 419-425. https://doi.org/10.18280/ isi. 250403

[8] Chattopadhyay R, Tham C. K. (2020). Fully and Partially Distributed Incentive Mechanism for a Mobile Edge Computing Network. IEEE Transactions on Mobile Computing, 99: 1-1. https://doi.org/10.1109/tmc.2020.3003079

[9] Mahmoud, M. E., Shen, X. (2011). FESCIM: fair, efficient, and secure cooperation incentive mechanism for multihop cellular networks. IEEE Transactions on Mobile Computing, 11(5): 753-766. https://doi.org/10.1109/tmc.2011.92

[10] Nian, F., Liu, R., Cong, A. (2020). An incentive mechanism model based on the correlation between neighbor behavior and distance. International Journal of Modern Physics C, 31(11): 2050161. https://doi.org/10.1142/s0129183120501612

[11] Chandrasekharan, I., Kumar, R.S., Ravindranath, M., Kushwah, D. J. (2010). Incentive mechanism for preventing deforestation and promoting conservation of forest ecosystem. Current Science, 98(4): 489-498.

[12] Andrés, C. (2010). Higher education. Training of excellence and seizing talent for internationalisation. Chemistry - A European Journal, 16(48): 14354-64.

[13] Collard, A., Gelaes, S., Vanbelle, S., Bredart, S., Defraigne, J. O., Boniver, J., Bourguignon, J. P. (2009). Reasoning versus knowledge retention and ascertainment throughout a problem - based learning curriculum. Medical education, 43(9): 854-865. https://doi.org/10. $\underline{1111 / j .1365-2923.2009 .03410 . x}$

[14] Qi, Y.M., Wang, J.G. (2020). A Talent Cultivation Model for Improving the Innovation Ability of College Students in Scientific Research, International Journal of Emerging Technologies in Learning, 15(18), 151-164. https://doi.org/10.3991/ijet.v15i18.16745

[15] Casey, A., Hughes, J., Izard, R. M., Greeves, J. P. (2014). Supplement use by UK-based British Army soldiers in training. British journal of nutrition, 112(7): 1175-1184. https://doi.org/10.1017/s0007114514001597

[16] Levy, M. D., Loy, L., Zatz, L. Y. (2014). Policy approach to nutrition and physical activity education in health care professional training. The American journal of clinical nutrition, 99(5): 1194S-1201S. https://doi.org/10.3945/ajen.113.073544

[17] Zeng, P., Yang, J., Fan, Z., Yang, C., Wang, H. (2016). A new policy by attending specialist standardization training for medical personnel. International journal of cardiology, 209: 213214. https://doi.org/10.1016/j.ijcard.2016.02.008

[18] Liu, J., Liao, C.X., Zhang, L.S. (2020). Research on the Incentive Mechanism of Innovation and Entrepreneurship in Higher Vocational Colleges. DEStech Transactions on Social Science Education and Human Science. https://doi.org/10.12783/dtssehs/icesd2020/34045

[19] Encaoua, D., Guellec, D., Martínez, C. (2006). Patent systems for encouraging innovation: Lessons from economic analysis. Research policy, 35(9): 1423-1440. https://doi.org/10. 1016/j.respol.2006.07.004

[20] Fan, B., Ju, X.F. (2008). Incentive mechanism research on knowledge sharing in enterprises based on principal-agent theory. Journal of Knowledge Management, 965-970. https://doi. org/10.1109/icmse.2008.4669029

[21] Vossler, C. A., Poe, G. L., Schulze, W. D., Segerson, K. (2006). Communication and incentive mechanisms based on group performance: An experimental study of nonpoint pollution control. Economic Inquiry, 44(4): 599-613. https://doi.org/10.1093/ei/cbj043

[22] Yanadori, Y., Cui, V. (2013). Creating incentives for innovation? The relationship between pay dispersion in R\&D groups and firm innovation performance. Strategic Management Journal, 34(12): 1502-1511. https://doi.org/10.1002/smj.2071 
[23] Murray, F., Stern, S., Campbell, G., MacCormack, A. (2012). Grand Innovation Prizes: A theoretical, normative, and empirical evaluation. Research Policy, 41(10): 1779-1792. https://doi.org/10.1016/j.respol.2012.06.013

\section{Authors}

Jialin Zuo is an associate professor working on Hebei Jiaotong Vocational and Technical College. She graduated from Hebei Normal University. Her research interests include education and student management, she has published more than 3 papers published and 1 book published. (Email: zuo0616zuo@126.com).

Wei Lu is an associate professor working on Hebei Jiaotong Vocational and Technical College. She graduated from Huaibei Normal University. Her research interests include education and student management, she has published more than 3 papers published and 1 book published. (Email:1u0727lu@126.com).

Chunxu Jia is an associate professor working on Hebei Jiaotong Vocational and Technical College. She graduated from Hebei Normal University. Her research interests include education and student management, she has published more than 3 papers published and 1 book published (Email: jia810jia@126.com).

Article submitted 2021-09-11. Resubmitted 2021-10-11. Final acceptance 2021-10-12. Final version published as submitted by the authors. 